\title{
Cytotoxicity and Biological Efficacy of Exendin-4-Encapsulated Solid Lipid Nanoparticles in INS-1 Cells
}

\author{
Hee-Sook Jun, ${ }^{1,2,3}$ Gongdeuk Bae, ${ }^{1}$ Young Tag Ko, ${ }^{3}$ and Yoon Sin $\mathrm{Oh}^{1,2}$ \\ ${ }^{1}$ Lee Gil Ya Cancer and Diabetes Institute, Gachon University, Incheon 406-840, Republic of Korea \\ ${ }^{2}$ Gachon Medical Research Institute, Gil Hospital, Incheon 405-760, Republic of Korea \\ ${ }^{3}$ College of Pharmacy, Gachon University, Incheon 406-799, Republic of Korea
}

Correspondence should be addressed to Yoon Sin Oh; with62@gachon.ac.kr

Received 11 June 2015; Accepted 24 August 2015

Academic Editor: Aran Son

Copyright (C) 2015 Hee-Sook Jun et al. This is an open access article distributed under the Creative Commons Attribution License, which permits unrestricted use, distribution, and reproduction in any medium, provided the original work is properly cited.

\begin{abstract}
Exendin-4 (Ex-4), a peptide of glucagon-like peptide-1 receptor agonist, is a potent insulinotropic agent and alternative drug delivery systems to increase therapeutic utility have been explored. We developed exendin-4-encapsulated solid lipid nanoparticles (Eudragit Ex-4 SLNs) and compared the effects of Eudragit Ex-4 SLNs with those of native Ex-4 on INS-1 cells. We observed no significant toxic effects of nanoparticles at concentrations from $1 \mathrm{nM}$ to $100 \mathrm{nM}$. Similar to Ex-4, Eudragit Ex-4 SLNs stimulated the production of cyclic AMP at $10 \mathrm{nM}$. Moreover, unlike treatment with the vehicle, treatment with $10 \mathrm{nM}$ Eudragit Ex-4 SLNs increased insulin mRNA levels and insulin secretion. These insulinotropic effects of Eudragit Ex-4 SLNs were comparable to those of Ex-4. Thus, our in vitro results suggest that the biological effects of Eudragit Ex-4 SLNs are similar to those of Ex-4, and further in vivo pharmacokinetic studies are required to propose an alternative sustained release drug system.
\end{abstract}

\section{Introduction}

Exendin-4 (Ex-4), the first clinically available incretin mimetics, is an analog of glucagon-like peptide-1 (GLP-1) [1]. Ex-4 is resistant to dipeptidyl peptidase-IV and thus is 3000 -fold more effective than GLP-1 [2]. Ex-4 is a GLP-1 receptor agonist with several glucoregulatory effects such as glucose-dependent increase in insulin secretion, suppression of glucagon secretion, and reduction of gastric mobility and food intake $[3,4]$. Exenatide, a synthetic version of Ex-4, is approved as a promising therapy for the treatment of patients with type 2 diabetes $[5,6]$. Exenatide is administered via frequent subcutaneous (SC) injections; therefore, an alternative route of administration such as the oral route is being examined to increase its therapeutic utility $[7,8]$. Recent studies have shown that nanosized drug delivery systems increase solubility, decrease side effects, prolong pharmacological effects, and improve bioavailability $[9,10]$. Solid lipid nanoparticles (SLNs) are particles made from crystalline solid lipids and have a mean diameter of 50 $1000 \mathrm{~nm}$ [11]; their advantages include controlled drug release and drug targeting, protection of the incorporated compound against chemical degradation, lack of carrier biotoxicity, and no problems associated with large-scale production [1113]. In recent studies, different combinations of solid lipid materials having various physicochemical properties have been examined for encapsulation of peptide drugs $[14,15]$. To develop an extended delivery system for Ex-4, we used solid lipid nanoparticles for encapsulation of Ex-4. In this study, we prepared Ex-4-loaded SLNs using Precirol, and we first compared its biological effects with those of native Ex-4 in INS-1 beta cells before further study. We found that biological effects of Ex-4-loaded SLNs are comparable to those of Ex-4.

\section{Methods}

2.1. Reagents. Precirol was obtained from Gattefosse (Gennevilliers, France) and Eudragit L30 D55 with PlasAcryl HTP 20 was purchased from EVONIK (Lafayette, Indiana, USA). Native Ex-4 was from Tocris Bioscience (Bristol, United Kingdom). Insulin enzyme immunoassay (EIA) kits were purchased from Alpco Diagnostics (Windham, NH, 
USA) and competitive cyclic adenosine $3^{\prime} 5^{\prime}$-monophosphate (cAMP) immunoassay kit was from Enzo Life Sciences (Plymouth Meeting, PA, USA). All other biochemical reagents, unless otherwise specified, were obtained from Sigma (St. Louis, MO, USA) or Invitrogen (Carlsbad, CA, USA).

2.2. Cell Culture. INS-1 cells were derived from a rat insulinoma and were maintained in a monolayer culture in Roswell Park Memorial Institute- (RPMI-) 1640 medium containing $11 \mathrm{mmol} / \mathrm{L}$ glucose. The culture medium was supplemented with $10 \%$ fetal bovine serum (FBS), 100 units/mL penicillin, and $100 \mu \mathrm{g} / \mathrm{mL}$ streptomycin.

2.3. Preparation of Eudragit-Coated Ex-4 SLNs. Precirol was dissolved in dichloromethane and the mixture with Ex4 (internal water phase) was dispersed by ultrasonication (Vibracell VCX130; Sonics, USA) at $20 \mathrm{amp}, 2$ pulses, to form a primary water-in-oil (W/O) emulsion. A double emulsion (W/O/W) was formed after addition of Tween 80 solution followed by sonication at $20 \mathrm{amp}, 2$ pulses. The organic solvent was evaporated using a rotary evaporator thus producing the SLN dispersion. This SLN dispersion was mixed with $1 \%$ of equal volume of Eudragit (Eudragit L30 D55 with PlasAcryl HTP 20) under magnetic stirring at $600 \mathrm{rpm}$ for $10 \mathrm{~min}$. The resulting formulation was Eudragit-coated Ex-4 SLNs (Eudragit Ex-4 SLNs) and Eudragit blank SLNs were used as controls.

2.4. Cytotoxicity Assay of Nanoparticles Using INS-1 Cells. We determined the cytotoxicity of Eudragit Ex-4 SLNs or Eudragit blank SLNs in INS-1 cells by examining the dehydrogenase activity. The cells were plated in 96-well plates and were incubated with various concentrations of Eudragit blank SLNs and Eudragit Ex-4 SLNs (final concentrations: $1 \sim 100 \mathrm{nM}$ ) at the indicated times. The number of viable cells was examined using the cell counting kit-8 (CCK-8) assay kit (Dojindo Lab., Kumamoto, Japan). Briefly, $10 \mu \mathrm{L}$ of CCK-8 solution was added to each well and the plate was incubated at $37^{\circ} \mathrm{C}$ for $2 \mathrm{~h}$. The absorbance of each well was measured at $450 \mathrm{~nm}$ using a microplate reader (Molecular Devices Corp., Menlo Park, USA).

2.5. Measurement of Intracellular cAMP Levels. INS-1 cells were plated on 12-well plates and after overnight glucose starvation, cells were treated with various concentrations of Eudragit blank SLNs, Eudragit Ex-4 SLNs, and Ex-4. The treated cells were extracted using $0.1 \mathrm{M} \mathrm{HCl}$ to avoid degradation of CAMP, and CAMP levels were measured in whole cell lysates by using the competitive cAMP immunoassay kit (Enzo Life Sciences) according to the manufacturer's instructions. The level of cAMP production was normalized to the amount of total protein.

2.6. Glucose-Stimulated Insulin Secretion Assay. Before the secretion experiments, the standard culture medium containing $11.1 \mathrm{mmol} / \mathrm{L}$ glucose was switched to a medium containing $5 \mathrm{mmol} / \mathrm{L}$ glucose. The insulin secretion was assayed as described previously [16]. The amount of insulin released into the supernatant was quantified using an insulin EIA kit (Alpco Diagnostics) according to the manufacturer's instructions. The amount of insulin release was normalized to the amount of total protein.

2.7. RNA Isolation and Quantitative Real-Time Polymerase Chain Reaction ( $q R T-P C R)$. RNA isolation was performed as described previously [17], and qRT-PCR analysis was performed using SYBR master mix (Takara) using ABI 7900 HT detection system (Applied Biosystems, Carlsbad, CA, USA). The relative mRNA transcript levels were calculated according to the $2^{-\Delta \mathrm{CT}}$ method, in which $\Delta \mathrm{CT}$ represents the differences in threshold cycle values between the target mRNA and cyclophilin internal control. Primer sequences were as follows: $5^{\prime}$-GCTTTTGTCAAACAGCACCTTTG- $3^{\prime}$ and $5^{\prime}$-CTCCCCACACACCAGGTAGAG- $3^{\prime}$ for insulin and $5^{\prime}$-GGTCTTTGGGAAGGTGAAAGAA- $3^{\prime}$ and $5^{\prime}$ GCCATTCCTGGACCCAAAA-3' for cyclophilin.

2.8. Statistical Analysis. Results were expressed as mean \pm standard error of mean (SEM) of three separate experiments and were analyzed using one-way analysis of variance (ANOVA). ANOVA followed by Scheffe's multiple test was used to determine the significance of any differences among more than two groups. $P<0.05$ was considered significant.

\section{Results and Discussion}

Most of the existing nanocarriers for oral delivery of Ex4 are polymer-based nanoparticles, such as chitosan and polylactide glycolic acid (PLGA) nanoparticles [8, 18], but polymeric nanoparticles have disadvantages such as poor bioavailability and low chemical and enzyme stability [19]. A lipid-based delivery system can overcome the disadvantages of the polymeric system, and the use of such a system for the delivery of insulin has been examined [15, 20]. Few studies have examined the use of such lipid systems for oral delivery of Ex-4; however, in a recent study, Ex-4loaded nanoparticles with a mixed lipid shell and an aqueous core containing micelles for improved hypoglycemic control have been examined [21]. In this study, Ex-4-loaded sodium cholate micelles were used as the inner aqueous phase, and this nanoparticle greatly enhanced the cellular uptake and transport of encapsulated Ex-4. In our study, Precirol, a glycerol palmitostearate, was used for the encapsulation of Ex-4 as a solid lipid (Figure 1). Precirol based SLNs showed lowparticle size, high encapsulation and loading efficiency, and long-term physical stability [22]. Moreover, solid state slows down their digestion by pancreatic lipase [23] and Precirol based SLNs can be orally administered for a controlled release in the gastrointestinal tract [24]. To determine whether the Ex-4 SLNs could be an alternative to Ex-4, we examined their biological effects such as insulinotropic effects and compared them with those of native Ex-4 on the pancreatic beta cell line INS-1.

3.1. Eudragit Ex-4 SLNs Have No Cellular Toxicity. To evaluate toxicity associated with the nanomaterials, we measured the 


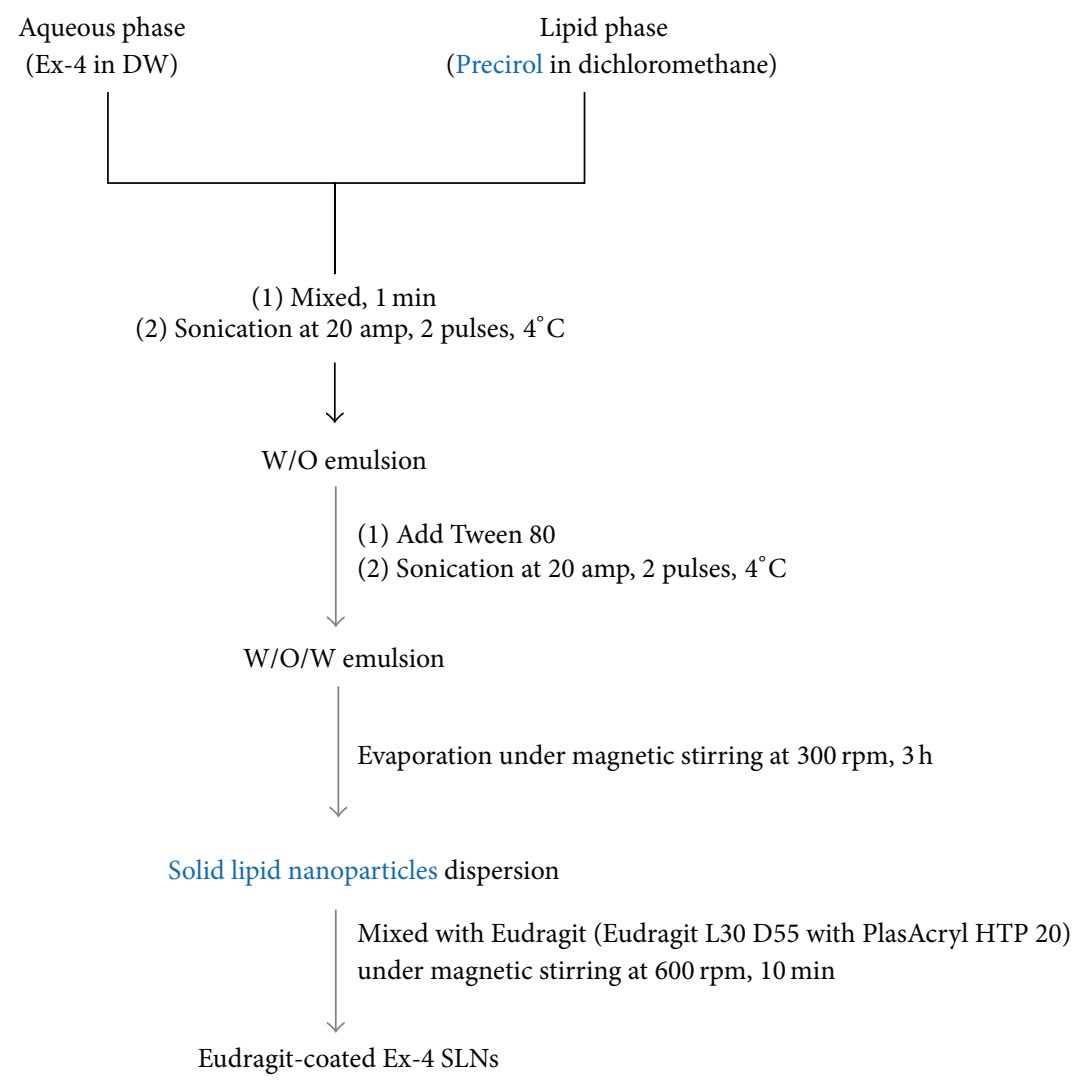

FIGURE 1: Encapsulation process of exendin-4 into solid lipid nanoparticles. The solid lipid system using Precirol was used for encapsulation of Ex-4 and nanoparticles were prepared by double emulsion (W/O/W) method.

viability of INS-1 cells incubated with different concentrations of the nanoparticles. The cells were treated with 1 to $100 \mathrm{nM}$ of nanoparticles with (Eudragit Ex-4 SLNs) or without Ex4 (Eudragit blank SLNs), and cell viability was measured using CCK assay at 24 (Figure 2(a)) and $48 \mathrm{~h}$ (Figure 2(b)). Treatment with the nanoparticles did not have any significant effects on cell viability, thereby confirming the safety of the carrier system (Figure 2). Compared to some polymeric nanoparticles, SLNs are generally less toxic because of the physiological and biocompatible lipids utilized in the manufacturing process [25]. Moreover, the material used for enteric coating (Eudragit L30D55), which can protect Ex-4 from the acidic environment in the stomach, itself is not cytotoxic [26]; therefore, Eudragit Ex-4 SLNs could be used as an alternative drug system in vivo.

3.2. Similar to Native Ex-4, Eudragit Ex-4 SLNs Increase cAMP Production. Ex-4 binds to the GLP-1 receptor (GLP$1 R$ ) coupled with Gs proteins, which stimulates adenylate cyclase and thus leads to an increase in the intracellular cAMP levels and an activation of protein kinase A (PKA) [27]. To determine whether nanoparticles impaired the ability of the Ex-4 moiety to activate the GLP-1R, we compared the potency of Eudragit Ex-4 SLNs with that of native Ex4. We used a competitive cAMP assay to monitor liganddependent GLP-1R activation in INS-1 cells expressing GLP1R. $10 \mathrm{nM}$ Eudragit Ex-4 SLNs showed increase in the cAMP levels and the levels were maintained by $100 \mathrm{nM}$ treatment (Figure 3). Moreover, Göke et al. showed that RINm5F cells had maximum levels of intracellular cAMP after treatment with $10 \mathrm{nM}$ Ex-4 [28]. In contrast, Eudragit blank SLNs did not alter the cAMP levels. Ex-4 seemed slightly more efficient in stimulating CAMP production than Eudragit Ex-4 SLNs; however, the increase was not significant. These results suggested that the receptor binding affinities of Eudragit Ex-4 SLNs were not different from those of Ex-4.

3.3. Eudragit Ex-4 SLNs Showed Activity Similar to Ex-4 on the Induction of Insulin mRNA Levels and Glucose-Stimulated Insulin Secretion. Physiologically, the activation of GLP-1R via Ex-4 stimulates insulin secretory capacity by augmenting the transcription of insulin gene and proinsulin synthesis and potentiates glucose-stimulated insulin secretion in pancreatic beta cells [29]. Therefore, we investigated the insulinotropic activities of Eudragit Ex-4 SLNs in INS-1 cells. Highest levels of cAMP production were observed at $10 \mathrm{nM}$; therefore, we evaluated insulin transcription levels and glucosestimulated insulin secretion after treatment for $24 \mathrm{~h}$ under this condition. Compared to the vehicle, Eudragit Ex-4 SLNs increased the insulin mRNA levels, and the level of induction was similar to that of Ex-4 (Figure 4(a)). At low glucose levels (3 mM glucose), the untreated group (nontreated), Eudragit blank SLNs, Ex-4, and Eudragit Ex-4 SLNs had no effect on insulin release. However, treatment with high 


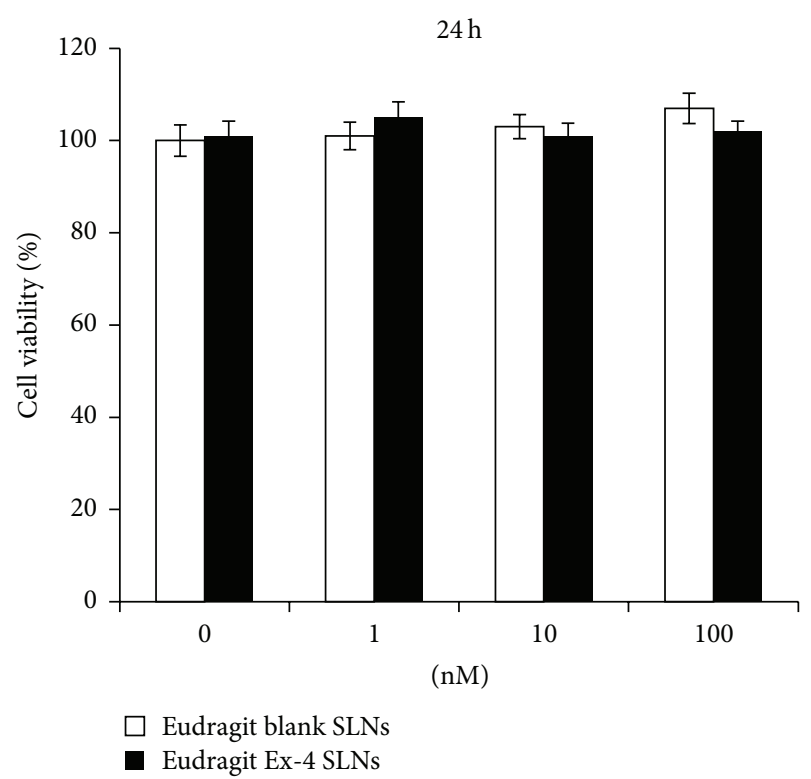

(a)

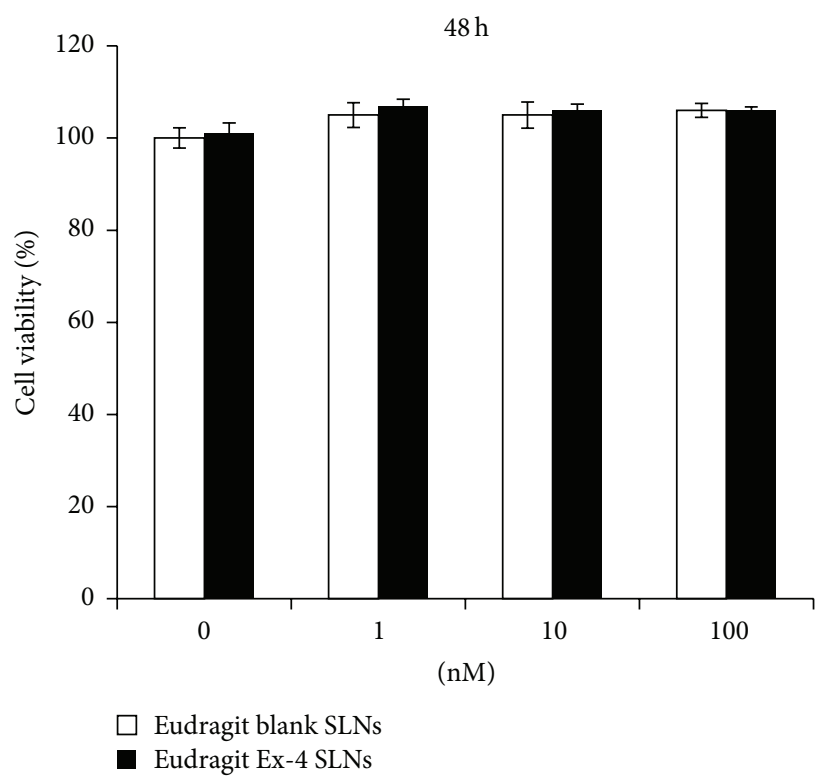

(b)

FIGURE 2: Cellular toxicity test of Eudragit exendin-4-encapsulated solid lipid nanoparticles on INS-1 cells. The number of viable INS-1 cells was determined after incubation with various concentrations of Eudragit blank solid lipid nanoparticles (SLNs) and Eudragit exendin-4 (Ex-4) SLNs for indicated times ((a) $24 \mathrm{~h}$; (b) $48 \mathrm{~h}$ ). Relative cell numbers are expressed as fold changes over nontreated cells. Data were represented as mean \pm standard error of mean (SEM; $n=3)$.

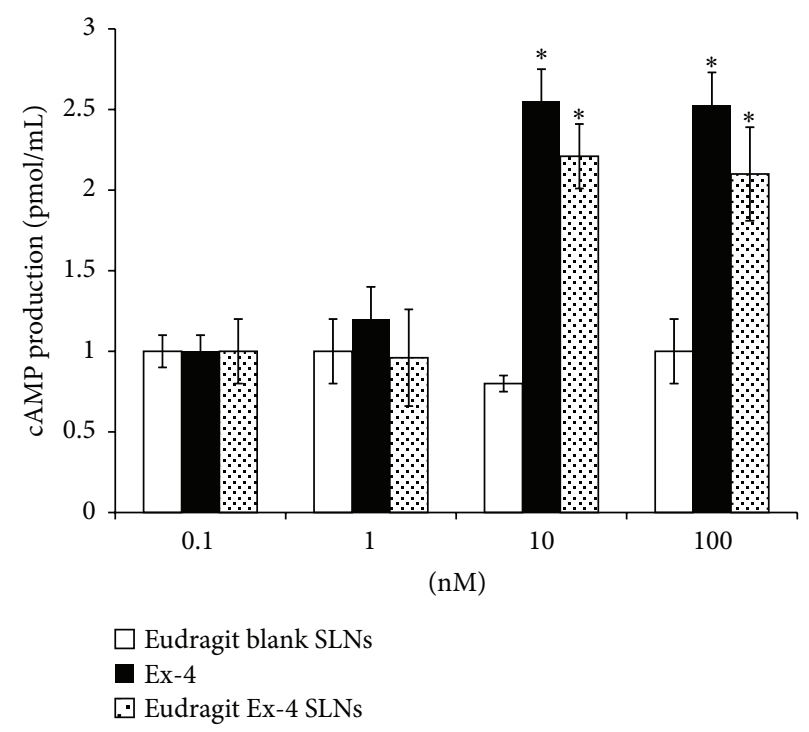

FIGURE 3: cAMP production in Eudragit exendin-4-encapsulated solid lipid nanoparticles-treated INS-1 cells. INS-1 cells were treated with different concentrations of exendin-4 (Ex-4), Eudragit blank solid lipid nanoparticles (SLNs), and Eudragit Ex-4 SLNs for 15 min and the cells were extracted using $0.1 \mathrm{M} \mathrm{HCl}$. cAMP production was examined in the whole cell lysate using competitive cAMP immunoassay kit. Data were represented as mean \pm standard error of mean (SEM; $n=3) .{ }^{*} P<0.05$ versus Eudragit blank SLNs.

glucose $(17 \mathrm{mM})$ induced insulin secretion (nontreated), and treatment with Eudragit blank SLNs showed a similar rate of insulin secretion as that in nontreated cells. Compared to Eudragit blank SLNs, Eudragit Ex-4 SLNs significantly increased insulin secretion at high glucose concentrations. In addition, native Ex-4 increased the insulin secretion similar to that by Eudragit Ex-4 SLNs (Figure 4(b)). These results suggest that Eudragit Ex-4 SLNs had similar effects on insulin secretion to those of native Ex-4. To determine the potential use of Eudragit Ex-4 SLNs as potent oral antidiabetic agents, the hypoglycemic effects of Eudragit Ex-4 SLNs in an animal model of diabetes will be investigated in future studies. 


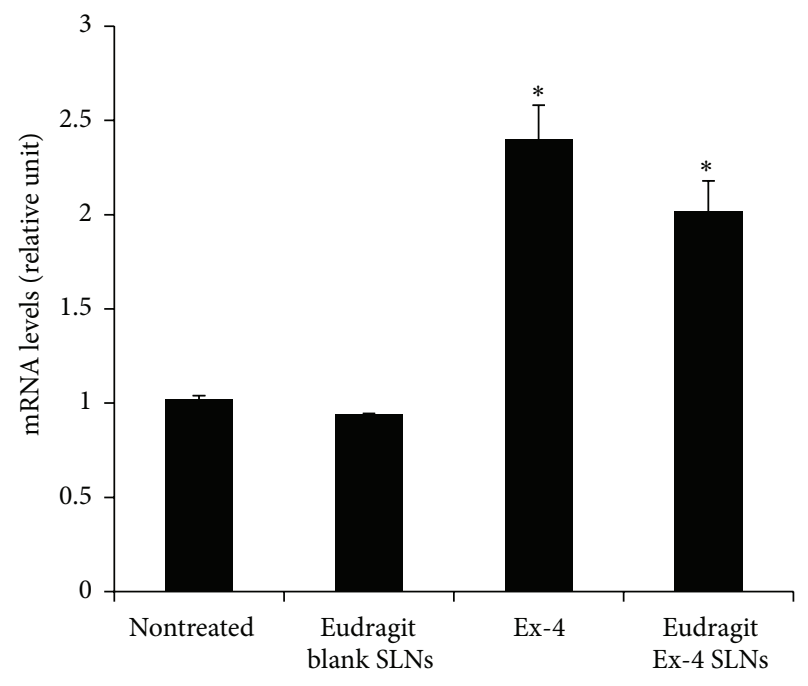

(a)

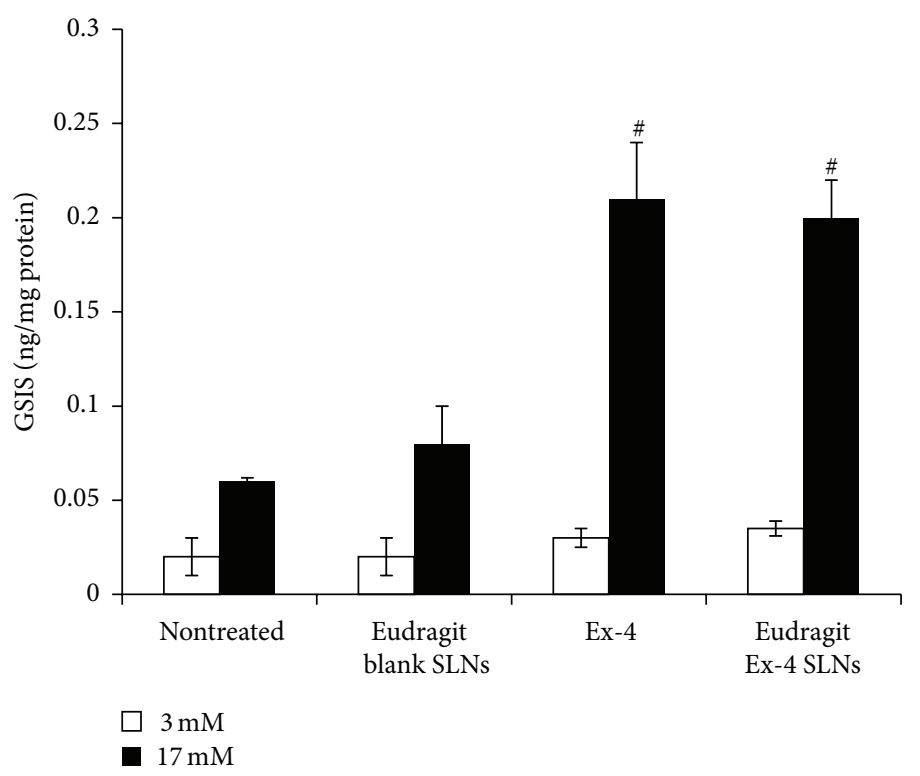

(b)

FIGURE 4: Insulinotropic activities of Eudragit exendin-4-encapsulated solid lipid nanoparticles in INS-1 cells. (a) Exendin-4 (Ex-4), Eudragit blank solid lipid nanoparticles (SLNs), and Eudragit Ex-4 SLNs were incubated for $24 \mathrm{~h}$, and the insulin mRNA levels were examined using quantitative real-time polymerase chain reaction (qRT-PCR) analysis. Cyclophilin was used as an internal control. (b) Cells were treated as described above, and after $24 \mathrm{~h}$, the cells were incubated in low $(3 \mathrm{mM})$ or high $(17 \mathrm{mM})$ concentration of glucose. The amount of insulin released into the supernatant was quantified using a rat insulin enzyme immunoassay (EIA) kit, and the level of insulin was normalized to the total amount of protein. Data were represented as mean \pm standard error of mean (SEM; $n=3),{ }^{*} P<0.05$ versus Eudragit blank SLNs, \# $<0.05$ versus $17 \mathrm{mM}$ treated Eudragit blank SLNs.

\section{Conclusion}

Ex-4-loaded Precirol based SLNs were prepared using a simple process based on the double emulsion technique. The Ex-4 nanoparticles had no cytotoxic effects and increased the cAMP activity similar to that induced by Ex-4 and consequently facilitated insulin secretion in response to high glucose concentrations. These in vitro results indicated that Eudragit Ex-4 SLNs have biological efficacies similar to those of Ex-4, and further studies about the time dependence of the biological effect of Eudragit Ex-4 SLNs in vitro and in animal models are required to determine the use of Eudragit Ex-4 SLNs for sustained release or oral delivery.

\section{Conflict of Interests}

The authors declare that there is no conflict of interests regarding the publication of this paper.

\section{Acknowledgment}

This study was supported by a grant from Korea Health Technology R\&D Project through Korea Health Industry Development Institute (KHIDI), funded by the Ministry of Health \& Welfare, Republic of Korea (Grant no. HI14C1135).

\section{References}

[1] J. Eng, W. A. Kleinman, L. Singh, G. Singh, and J.-P. Raufman, "Isolation and characterization of exendin-4, an exendin-3 analogue, from Heloderma suspectum venom. Further evidence for an exendin receptor on dispersed acini from guinea pig pancreas," Journal of Biological Chemistry, vol. 267, no. 11, pp. 7402-7405, 1992.

[2] D. J. Drucker and M. A. Nauck, "The incretin system: glucagonlike peptide-1 receptor agonists and dipeptidyl peptidase-4 inhibitors in type 2 diabetes," The Lancet, vol. 368, no. 9548, pp. 1696-1705, 2006.

[3] T. J. Kieffer, C. H. S. McIntosh, and R. A. Pederson, "Degradation of glucose-dependent insulinotropic polypeptide and truncated glucagon-like peptide 1 in vitro and in vivo by dipeptidyl peptidase IV," Endocrinology, vol. 136, no. 8, pp. 3585-3596, 1995.

[4] J. B. Buse, R. M. Bergenstal, L. C. Glass et al., "Use of twice-daily exenatide in basal insulin-treated patients with type 2 diabetes," Annals of Internal Medicine, vol. 154, no. 2, pp. 103-112, 2011.

[5] O. G. Kolterman, J. B. Buse, M. S. Fineman et al., "Synthetic exendin-4 (exenatide) significantly reduces postprandial and fasting plasma glucose in subjects with type 2 diabetes," Journal of Clinical Endocrinology and Metabolism, vol. 88, no. 7, pp. 3082-3089, 2003.

[6] L. L. Nielsen, A. A. Young, and D. G. Parkes, "Pharmacology of exenatide (synthetic exendin-4): a potential therapeutic for 
improved glycemic control of type 2 diabetes," Regulatory Peptides, vol. 117, no. 2, pp. 77-88, 2004.

[7] H.-N. Nguyen, S.-P. Wey, J.-H. Juang et al., "The glucoselowering potential of exendin- 4 orally delivered via a $\mathrm{pH}$ sensitive nanoparticle vehicle and effects on subsequent insulin secretion in vivo," Biomaterials, vol. 32, no. 10, pp. 2673-2682, 2011.

[8] E.-Y. Chuang, G. T. H. Nguyen, F.-Y. Su et al., "Combination therapy via oral co-administration of insulin- and exendin-4loaded nanoparticles to treat type 2 diabetic rats undergoing OGTT," Biomaterials, vol. 34, no. 32, pp. 7994-8001, 2013.

[9] C.-F. Hung, C.-L. Fang, M.-H. Liao, and J.-Y. Fang, "The effect of oil components on the physicochemical properties and drug delivery of emulsions: tocol emulsion versus lipid emulsion," International Journal of Pharmaceutics, vol. 335, no. 1-2, pp. 193202, 2007.

[10] V. Teeranachaideekul, R. H. Müller, and V. B. Junyaprasert, "Encapsulation of ascorbyl palmitate in nanostructured lipid carriers (NLC)-effects of formulation parameters on physicochemical stability," International Journal of Pharmaceutics, vol. 340, no. 1-2, pp. 198-206, 2007.

[11] R. H. Müller, K. Mäder, and S. Gohla, "Solid lipid nanoparticles (SLN) for controlled drug delivery-a review of the state of the art," European Journal of Pharmaceutics and Biopharmaceutics, vol. 50, no. 1, pp. 161-177, 2000.

[12] E. Marengo, R. Cavalli, O. Caputo, L. Rodriguez, and M. R. Gasco, "Scale-up of the preparation process of solid lipid nanospheres. Part I," International Journal of Pharmaceutics, vol. 205, no. 1-2, pp. 3-13, 2000.

[13] W. Mehnert and K. Mäder, "Solid lipid nanoparticles: production, characterization and applications," Advanced Drug Delivery Reviews, vol. 47, no. 2-3, pp. 165-196, 2001.

[14] L. Battaglia, M. Trotta, M. Gallarate, M. E. Carlotti, G. P. Zara, and A. Bargoni, "Solid lipid nanoparticles formed by solventin-water emulsion-diffusion technique: development and influence on insulin stability," Journal of microencapsulation, vol. 24, no. 7, pp. 660-672, 2007.

[15] M. Gallarate, M. Trotta, L. Battaglia, and D. Chirio, "Preparation of solid lipid nanoparticles from W/O/W emulsions: preliminary studies on insulin encapsulation," Journal of Microencapsulation, vol. 26, no. 5, pp. 394-402, 2009.

[16] Y. S. Oh, Y.-J. Lee, E. Y. Park, and H.-S. Jun, "Interleukin6 treatment induces beta-cell apoptosis via STAT-3-mediated nitric oxide production," Diabetes/Metabolism Research and Reviews, vol. 27, no. 8, pp. 813-819, 2011.

[17] Y. S. Oh, Y.-J. Lee, Y. Kang, J. Han, O.-K. Lim, and H.-S. Jun, "Exendin-4 inhibits glucolipotoxic ER stress in pancreatic $\beta$ cells via regulation of SREBP1c and $\mathrm{C} / \mathrm{EBP} \beta$ transcription factors," Journal of Endocrinology, vol. 216, no. 3, pp. 343-352, 2013.

[18] M. Wang, Y. Zhang, J. Feng et al., "Preparation, characterization, and in vitro and in vivo investigation of chitosan-coated poly (d,l-lactide-co-glycolide) nanoparticles for intestinal delivery of exendin-4," International Journal of Nanomedicine, vol. 8, pp. 1141-1154, 2013.

[19] A. C. Hunter, J. Elsom, P. P. Wibroe, and S. M. Moghimi, "Polymeric particulate technologies for oral drug delivery and targeting: a pathophysiological perspective," Maturitas, vol. 73, no. 1, pp. 5-18, 2012.

[20] P. Fonte, F. Andrade, F. Araújo, C. Andrade, J. D. Neves, and B. Sarmento, "Chitosan-coated solid lipid nanoparticles for insulin delivery," Methods in Enzymology, vol. 508, pp. 295-314, 2012.
[21] C. Chen, X. Zhu, Y. Dou et al., "Exendin-4 loaded nanoparticles with a lipid shell and aqueous core containing micelles for enhanced intestinal absorption," Journal of Biomedical Nanotechnology, vol. 11, no. 5, pp. 865-876, 2015.

[22] H. Hamishehkar, J. Shokri, S. Fallahi, A. Jahangiri, S. Ghanbarzadeh, and M. Kouhsoltani, "Histopathological evaluation of caffeine-loaded solid lipid nanoparticles in efficient treatment of cellulite," Drug Development and Industrial Pharmacy, pp. 17, 2014.

[23] L. Bonnaire, S. Sandra, T. Helgason, E. A. Decker, J. Weiss, and D. J. McClements, "Influence of lipid physical state on the in vitro digestibility of emulsified lipids," Journal of Agricultural and Food Chemistry, vol. 56, no. 10, pp. 3791-3797, 2008.

[24] R. H. Müller, D. Rühl, and S. A. Runge, "Biodegradation of solid lipid nanoparticles as a function of lipase incubation time," International Journal of Pharmaceutics, vol. 144, no. 1, pp. 115121, 1996.

[25] R. H. Müller, S. Maassen, C. Schwarz, and W. Mehnert, "Solid lipid nanoparticles (SLN) as potential carrier for human use: interaction with human granulocytes," Journal of Controlled Release, vol. 47, no. 3, pp. 261-269, 1997.

[26] J.-W. Yoo, N. Giri, and C. H. Lee, "PH-sensitive Eudragit nanoparticles for mucosal drug delivery," International Journal of Pharmaceutics, vol. 403, no. 1-2, pp. 262-267, 2011.

[27] R. Perfetti and P. Merkel, "Glucagon-like peptide-1: a major regulator of pancreatic $\beta$-cell function," European Journal of Endocrinology, vol. 143, no. 6, pp. 717-725, 2000.

[28] R. Göke, H.-C. Fehmann, T. Linn et al., "Exendin-4 is a high potency agonist and truncated exendin-(9-39)-amide an antagonist at the glucagon-like peptide 1-(7-36)-amide receptor of insulin-secreting $\beta$-cells," The Journal of Biological Chemistry, vol. 268, no. 26, pp. 19650-19655, 1993.

[29] C. Alarcon, B. Wicksteed, and C. J. Rhodes, "Exendin 4 controls insulin production in rat islet beta cells predominantly by potentiation of glucose-stimulated proinsulin biosynthesis at the translational level," Diabetologia, vol. 49, no. 12, pp. 2920 2929, 2006. 

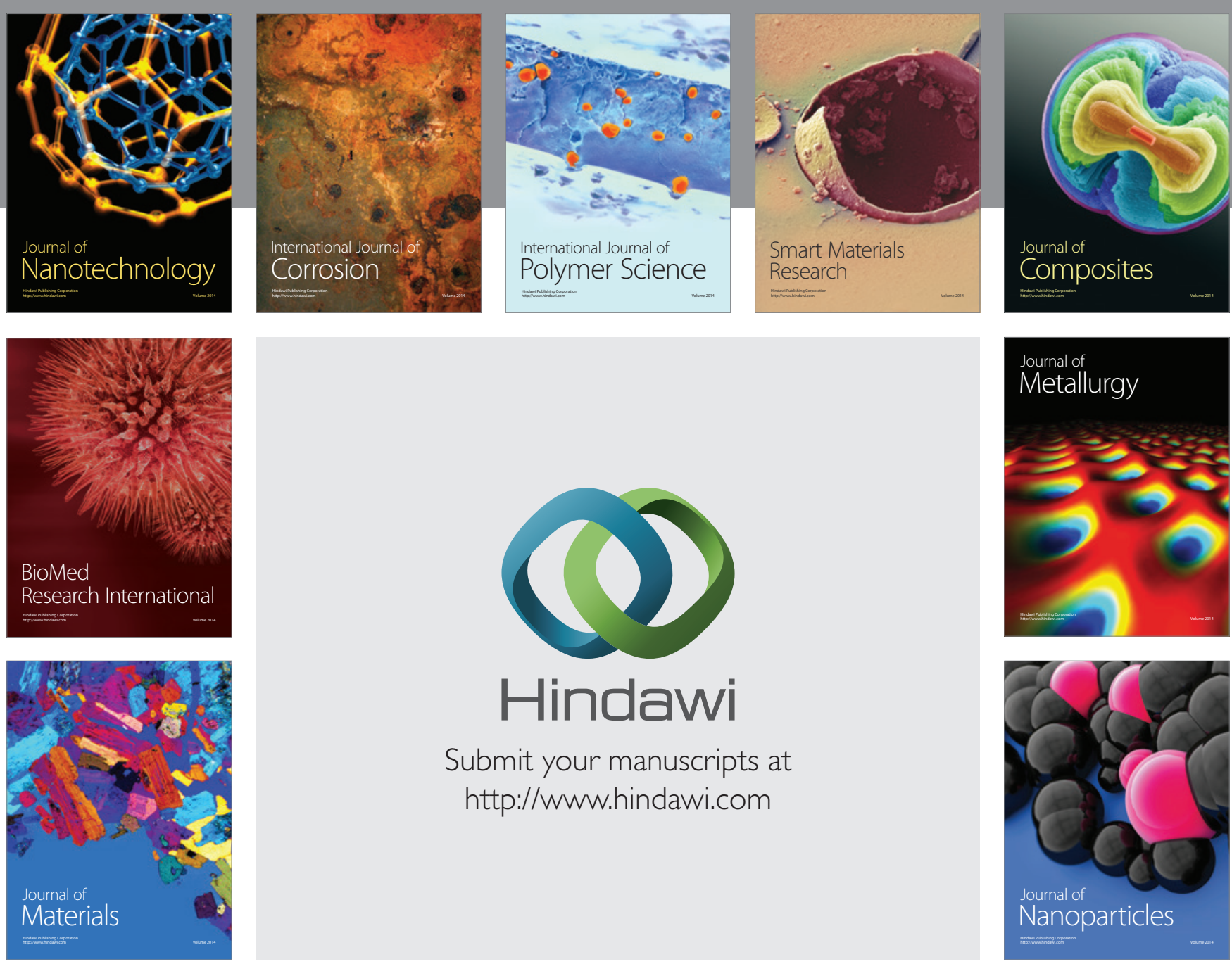

Submit your manuscripts at http://www.hindawi.com
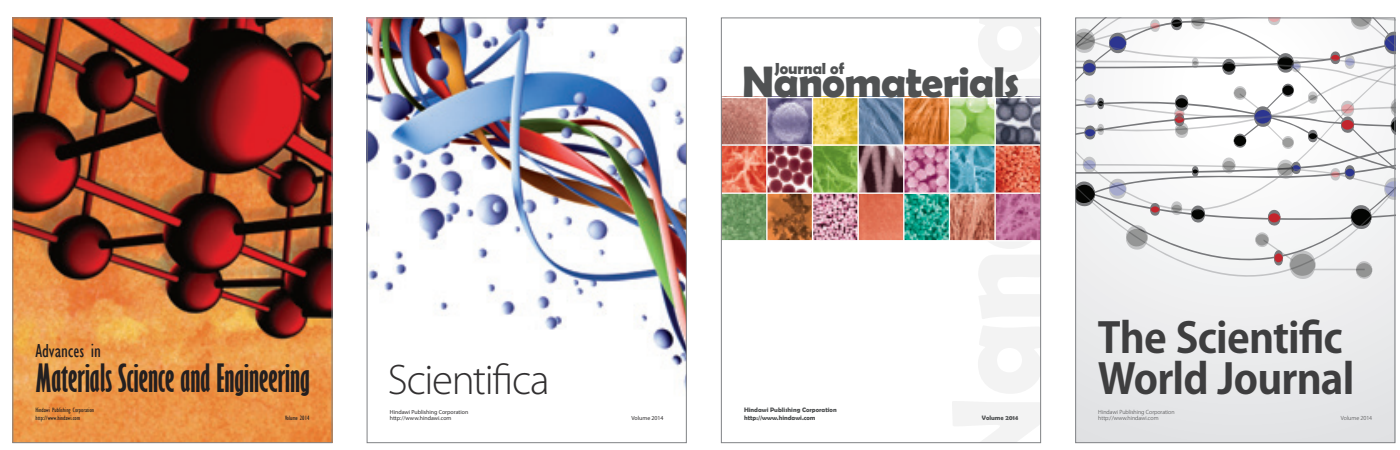

\section{The Scientific World Journal}
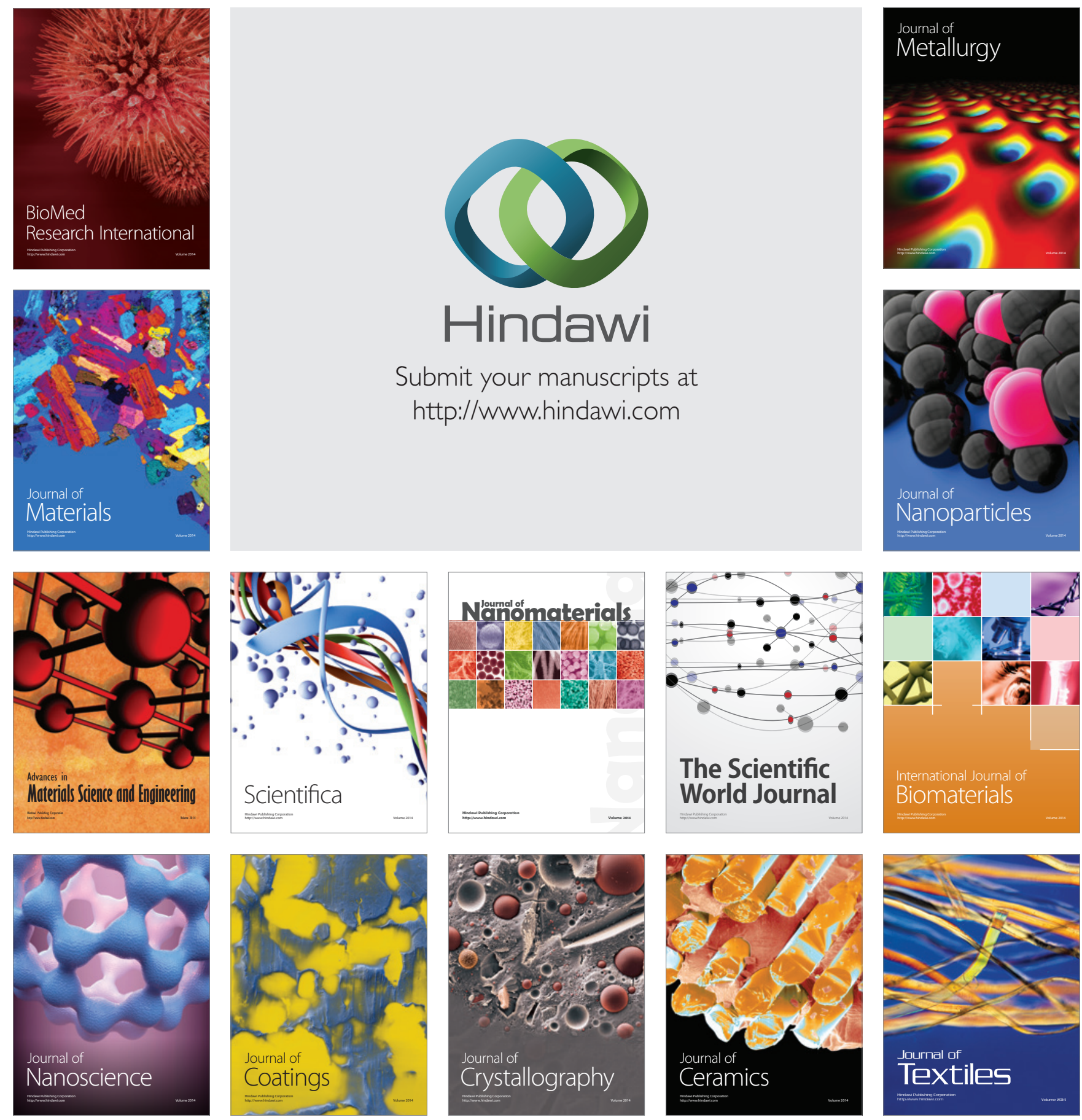